\title{
Assessment of the Acoustic Impact of Wind Farm Projects: Methodology and Case
}

\author{
Jose Molina-Ruiz ${ }^{*}$, Mari Luz García-Lorenzo², Carmen Pérez-Sirvent ${ }^{3}$, \\ María José Martínez-Sánchez ${ }^{3}$, Diego Gallego ${ }^{4}$ \\ ${ }^{1}$ Department of Geography, Faculty of Geography, University of Murcia, Murcia, Spain \\ ${ }^{2}$ Department of Mineralogy and Petrology, Faculty of Geology, University Complutense of Madrid, Madrid, Spain \\ ${ }^{3}$ Department of Agricultural Chemistry, Geology and Pedology, Faculty of Chemistry, University of Murcia, Murcia, Spain \\ ${ }^{4}$ Diego Gallego Cambronero Departamento Ecologia, Faculty of Sciences, University of Alicante, Alicante, Spain \\ Email: *mgarc17@ucm.es
}

How to cite this paper: Molina-Ruiz, J., García-Lorenzo, M.L., Pérez-Sirvent, C., Martínez-Sánchez, M.J. and Gallego, D. (2018) Assessment of the Acoustic Impact of Wind Farm Projects: Methodology and Case. Journal of Geoscience and Environment Protection, 6, 99-110.

https://doi.org/10.4236/gep.2018.61007

Received: November 13, 2017

Accepted: January 27, 2018

Published: January 30, 2018

Copyright (C) 2018 by authors and Scientific Research Publishing Inc. This work is licensed under the Creative Commons Attribution International License (CC BY 4.0).

http://creativecommons.org/licenses/by/4.0/

\begin{abstract}
Wind energy is a clean renewable and its benefits are considered greater than the disadvantages. However, even though wind farms represent environmentally friendly projects, they frequently generate public resistance. Wind turbines are socially controversial because of their visual and acoustic impacts. The aim of this work was to design a methodology for the preliminary evaluation of potential acoustic impact of wind farms. Three steps have been proposed: identification, characterization and assessment of the acoustic impact during the construction, operation and decommissioning phase. Obtained results in the studied area suggested that at a maximum power, at 500 meters of wind turbines, noise level is lower than the reference level established in the legislation. In summary, proposed methodology could help to determine and to evaluate the best location for new wind farm projects. Proposed methodology could help to determine and to evaluate the best location for new wind farm projects. Moreover, this method could be used as a consulting tool for public organizations and private institutions, being quick, concise and clear. Obtained results for the studied wind farm project suggested that almost all the area showed noise levels lower than established background noise level.
\end{abstract}

\section{Keywords}

Wind Turbine, Environmental Impact Assessment, Acoustic Impact, Wind Farm

\section{Introduction}

Renewable energies, and specially wind energy, have received a big impulse in 
the last decades. The 2009/28/EC Directive on the promotion of the use of energy from renewable sources sets the objective of reaching at least $20 \%$ of the EU's final energy consumption through renewable energy sources by 2020. The Spanish National Renewable Energy Action Plan (NREAP) splits the overall 20\% renewable energy target into $40.2 \%$ renewable electricity, $18.9 \%$ renewable heating and cooling and $13.6 \%$ into renewable transport [1].

Among them, wind energy has had the fastest growth rate among the renewable sources of energy over the past few decades due to its competitive price and mature technology. This has resulted in the widespread deployment of wind turbines in rural communities [2]. Even if this energy has a "clean" image, it is not difficult to find unfavourable positions regarding the installation of wind farms [3] [4]. Opposition is mainly based on a combination of visual intrusion, bird-kill and noise impact [5] [6] [7]. Noise can have an effect on the environment, and can be therefore a material consideration in the determination of planning actions.

The Environmental Impact Assessment (EIA) of projects is a legal-administrative procedure for information collection, analysis and forecasting designed to foresee, prevent and correct the possible effects, both direct and indirect, of the execution of a particular project on the environment. As regards the legal framework, the European Community approved Directive 85/337/EEC, dated 27 June 1985 , on assessing the environmental impacts of certain public and private works [8].

European legislation on Environmental Impact Assessment has been incorporated into Spanish law through the Legislative Royal Decree 1302/1986, dated 28 June, on Environmental Impact Assessment, and the rules for its application approved by the Royal Decree 1131/1988, dated 30 September [9]. A definition and classification of impact types is included in Annex I of this Royal Decree (Table 1).

In the last few years, from the publication EU "Green Book" about future policies against noise until the directive 2002/49/CE appeared on July $25^{\text {th }} 2002$ [9], with the resulting transpositions to National Laws, as occurs in Spain with the publication of Law 37/2003, Noise Control Law [10], the result of this has been that both government authorities as well as the enterprises have begun to carry out new studies about the problem of environmental noise and also the study of new methods for assessing it. This law does not establish values, simply providing definitions and deadlines for the execution of noise maps.

Some regional bodies have their own rules regarding noise pollution because establishment of allowed maximum values is a regional competence. In the particular case of Murcia Region is the Decree 48/1998, of 30 July, of the Autonomous Region of Murcia on the Protection of the Environment against noise [11]. In this rule it is established that for natural reserves, the allowed maximum limit is established in $60 \mathrm{~dB}(\mathrm{~A})$ during the day and $50 \mathrm{~dB}(\mathrm{~A})$ at night.

The aim of this work was to design a methodology for the preliminary evalua- 
tion of potential acoustic impact of wind farms. For this aim three steps have been proposed: identification, characterization and assessment of the acoustic impact during the construction, operation and decommissioning phase.

In addition, the proposed methodology was applied to a particular case in Murcia Region (SE, Spain).

\section{Methodology}

In order to establish the methodology to identify, to characterise and to assess the acoustic impact of a wind farm it has been considered that operations could be grouped in three phases: construction, operation and decommissioning phase.

\subsection{Identification of Acoustic Impact}

\subsubsection{Construction Phase}

Throughout wind energy project construction, the entire area would be temporarily impacted by site preparation activities, such as clearing, construction of access and on-site roads, preparation and use of material and equipment lay-down areas, erection of turbines, construction of the electrical substation, central control facility and ancillary facilities, and installation of power and signal cables.

The acoustic impact in this phase has a punctual character and is mainly produced by heavy machinery. This impact could affect negatively to the fauna and to residents of close towns.

\subsubsection{Operation Phase}

No land-disturbing activities and associated impacts are expected during the operation phase. Routine operations include wind-driven operations of the turbines to produce power, and regular monitoring and maintenance activities to ensure safe and consistent operation.

Even if these impacts have a punctual character, since wind turbines are separated more than 100 metres and its effects are not summed, they could affect negatively to the fauna and to inhabitants of close towns.

\subsubsection{Decommissioning Phase}

Decommissioning of a wind farm would include removal of turbines, buildings, concrete pads, and foundations, and the excavation and removal of buried components. The acoustic impact in this phase has a punctual character and is mainly produced by heavy machinery. This impact could affect negatively to the fauna and to residents of close towns.

\subsection{Characterization of Acoustic Impact}

\subsubsection{Construction Phase}

In this phase the acoustic impact is considered as direct, negative, simple, temporary (short term), discontinuous, reversible, recoverable and compatible (Table $1)$. 
Table 1. Types of impacts established in the annex I, royal decree 1131/1988.

\begin{tabular}{|c|c|}
\hline Origin & Direct or indirect. \\
\hline Effect & $\begin{array}{l}\text { Positive or negative: A negative effect includes as "that as produces a loss in natural, cultural landscape...or the character } \\
\text { and personality of a determined locality". }\end{array}$ \\
\hline Evolution & $\begin{array}{l}\text { Simple: Only appears over one environmental indicator. } \\
\text { Cumulative: Prolonged, with a progressive increase in its level. } \\
\text { Synergic: Increased by the accumulation of different factors. }\end{array}$ \\
\hline Duration & $\begin{array}{l}\text { Temporary or permanent. } \\
\text { Short, medium or long term: The impact could be measured, respectively, within a time period of one year, five years or } \\
\text { greater permanent or temporary impact. }\end{array}$ \\
\hline Persistence & Continuous or discontinuous. \\
\hline Reversibility & $\begin{array}{l}\text { Reversible or irreversible: The impact Could be assimilated or reversed, or not, as the case may be, by the natural capacity of } \\
\text { the environment to recover. }\end{array}$ \\
\hline Recoverability & Recoverable or unrecoverable: The environment can, or cannot, be recovered by natural or human action. \\
\hline Impact & $\begin{array}{l}\text { Compatible: The effect on the environment will last only as long as the project and will cease upon termination. } \\
\text { Moderate: Recovery of the environment does not require mitigation measures. } \\
\text { Severe: Recovery of the environment requires mitigation and protective measures. } \\
\text { Critical: Above than an acceptable level. A permanent loss of environmental quality will be produced even after mitigating } \\
\text { measures. }\end{array}$ \\
\hline
\end{tabular}

\subsubsection{Operation Phase}

During this phase the acoustic impact is direct, negative, simple, temporary (short term for vehicles and long term for wind turbines), continuous, reversible, recoverable and compatible (Table 1).

\subsubsection{Decommissioning Phase}

Acoustic impact in this phase is similar to those in construction phase, that is, direct, negative, simple, temporary (short term), discontinuous, reversible, recoverable and compatible (Table 1 ).

\subsection{Assessment of Acoustic Impact}

In order to assess the acoustic impact, we propose to evaluate three different possibilities: minimum power, intermediate power and maximum power. Obtained results from these situations allow establishing noise maps, taking into account the effect of distance in noise mitigation.

Distance mitigation is calculated as follows:

$$
L_{p}=L_{w}-10 \times \log \left(2 \pi r^{2}\right)
$$

where:

$L_{p}=$ resulting noise level $(\mathrm{dB})$,

$L_{w}=$ noise level in emission source $(\mathrm{dB})$,

$r=$ Euclidean distance between wind turbine and point $(\mathrm{m})$.

To carry out the study we propose to consider 1 sampling point/hectare in the studied area, randomly selected. Then, by way of kriging interpolation, results could be extrapolated to the rest of the area. Obtained maps could be added as 
follows:

$$
L_{t}=L_{2}+10 \times \log \left(1+10^{0.1\left(L_{1}-L_{2}\right)}\right)
$$

where:

$L_{t}=$ resulting noise level $(\mathrm{dB})$ in each pixel,

$L_{i}=$ partial noise level $(\mathrm{dB})$ in each pixel.

Obtained results allow estimating noise generation for the simultaneous activity of all wind turbines.

In order to assess the acoustic impact, it is necessary to consider the background noise level. In this case, wind is the main background noise source. Wind turbines will generate more noise when increasing wind power, that is, increase of wind turbine noise is directly correlated with background noise increase. For this reason, background noise should be considered in its possible variations.

Calculation of background noise levels at different wind speeds is a difficult question since, even at low wind speed $(4 \mathrm{~m} / \mathrm{s})$, the sound level meter could be saturated registering wrong data. For this reason, some estimated indicative thresholds could be considered, as a function of average wind speed. Once background noise is estimated, a background noise map could be made, with a constant value for each considered power in the studied area.

\section{Application of Established Methodology to a Wind Farm Located in Murcia Region}

The studied wind farm is located in Murcia Region, with a surface of 171 hectares and 16 wind turbines with a rated power of $32 \mathrm{MW}$ and 2480 equivalent hours.

The calculation of noise levels was made bearing in mind three possibilities: minimum power $(60.9 \mathrm{~dB}(\mathrm{~A}))$, intermediate power $(68 \mathrm{~dB}(\mathrm{~A}))$ and maximum power (75.3 $\mathrm{dB}(\mathrm{A}))$, taking into account wind turbine manufacturer information.

A noise map was made for each wind turbine, considering the effect of distance in noise mitigation. For this study, 3400 sampling points, randomly distributed were selected, and, by way of kriging interpolation, results were extrapolated to the rest of the study area. At last, maps were added to obtain a final noise map.

Background noise level was also incorporated, considering that this level is a constant value for all the study area for each considered operation power.

That is, for minimum power and with a wind speed of $4 \mathrm{~m} / \mathrm{s}$, the background noise level is $40 \mathrm{~dB}(\mathrm{~A})$. For the intermediate power and with a wind speed of 7 $\mathrm{m} / \mathrm{s}$, the background noise level is $45 \mathrm{~dB}$ (A). Finally, for maximum power and with a wind speed of $21 \mathrm{~m} / \mathrm{s}$, the background noise level is $50 \mathrm{~dB}(\mathrm{~A})$. This value corresponds to the allowed maximum limit established in the current legislation in natural spaces during the night. 
Noise levels lower than background noise level could appear during the extrapolation process. This error could be corrected in the map legend, establishing that the maximum value of the first interval should be the background noise level. In our case, 6 intervals were established: (0-background noise level), (background noise level-60), (60 - 65), (65 - 70), (70 - 75) and (>75).

\subsection{Construction Phase}

Produced noise level during construction of access roads and concrete pads was determined.

- Access road construction: during this operation employed machinery and its noise level is summarised in Table 2 , and result map has been calculated as a sum of noise maps for all the machinery working at the same time (maximum possible noise) (Figure 1). For this calculation, wind speed has been considered in $7 \mathrm{~m} / \mathrm{s}$ and background noise level is $45 \mathrm{~dB}(\mathrm{~A})$. Almost all the studied area showed noise level lower than established background noise. Allowed maximum levels (>75 dB (A)) were exceeded in 15 hectares (Table 3).

The study area is not located in none of noise categories established in the Decree 48/1998 [12], and there is no applicable regulation.

- Concrete pad construction: employed machinery and its noise level is summarised in Table 2. Result map taking into account the maximum possible noise situation (Figure 2) showed that noise level ranged from 45 to 60 $\mathrm{dB}(\mathrm{A})$ for almost all the territory. Allowed maximum values were exceeded in 56 hectares (Table 3 ), corresponding to the concrete pad location.

\subsection{Operation Phase}

Noise level has been determined at 10, 50, 100 and 500 metres of the wind turbine, taking into account wind turbine manufacturer information (Table 4). Affected surface for each noise interval is summarized in Table 5, bearing in mind the 3 wind speed possibilities and the background noise level (Figures 3-5). For the three conditions, almost all the study area showed noise levels lower than background level.

The study zone does not present any figure of protection and is not located close to towns or cities (the most restrictive situations in the current legislation). Noise impact is slight in this phase and the admissible maximum value is only surpassed in 0.92 and 17.44 hectares, for $7 \mathrm{~m} / \mathrm{s}$ and $21 \mathrm{~m} / \mathrm{s}$ wind speed, respectively. In addition, it is important to consider that wind turbines are equipped with and automatic stop when wind speed is higher than $21 \mathrm{~m} / \mathrm{s}$ after $30 \mathrm{mi}$ nutes. Therefore, noise under these conditions will show a temporary and low term character.

\subsection{Decommissioning Phase}

Acoustic impact in this phase is similar to those in construction phase (Figure 2). 
Table 2. Estimated noise level for machinery used in the construction phase.

\begin{tabular}{ccccc}
\hline & Access roads construction & \multicolumn{2}{c}{ Concrete pad construction } \\
\hline & Unities & Noise level (dB (A)) & Unities & Noise level (dB (A)) \\
\hline Dump truck & 2 & 85 & 1 & 85 \\
Bulldozer & 1 & 90 & 1 & 123 \\
Grader & 1 & 85 & & \\
Scraper loader & 1 & 93 & & \\
\hline
\end{tabular}

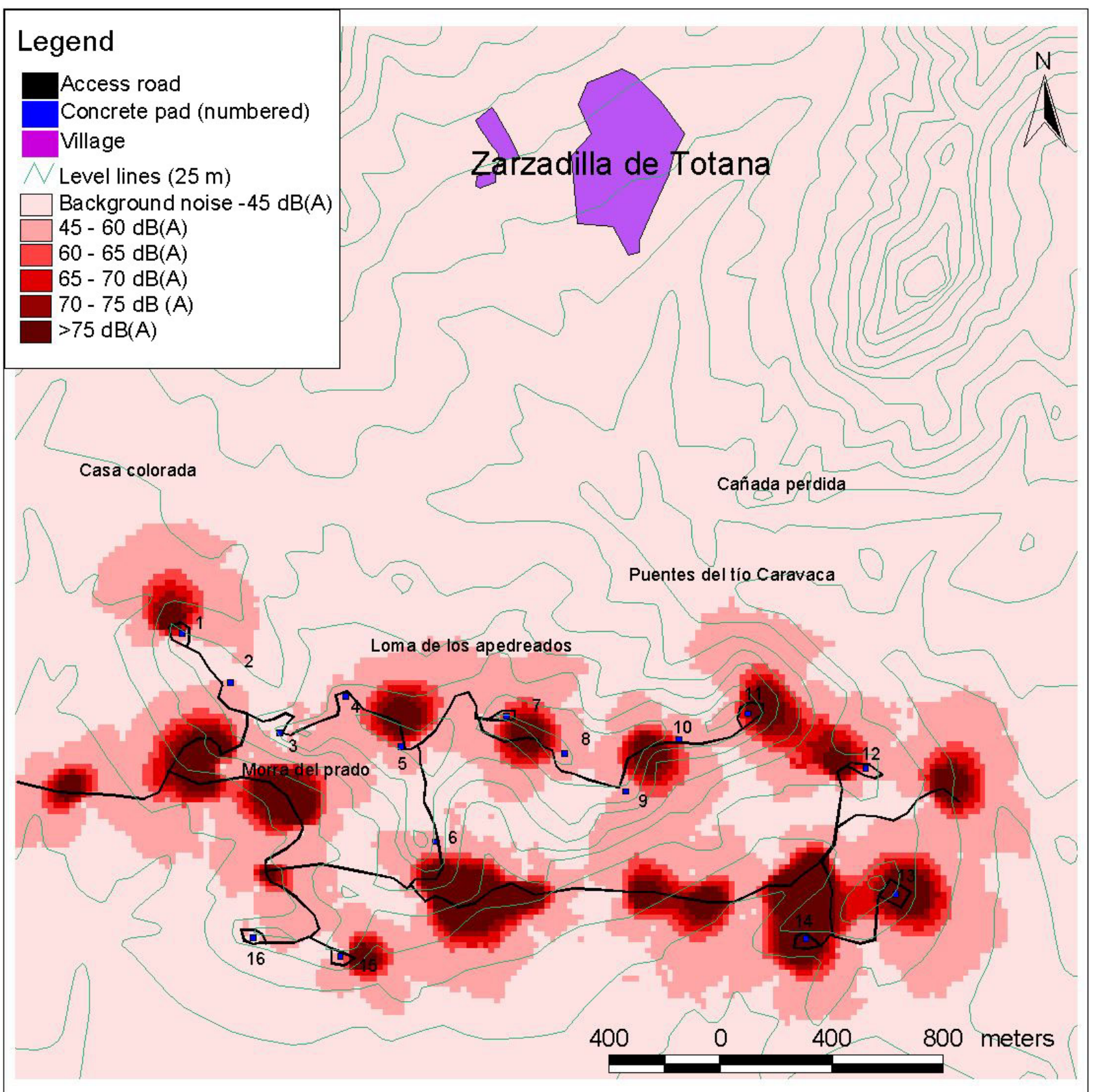

Figure 1. Noise map in construction phase: road construction. 
Table 3. Surface included in each established noise category.

\begin{tabular}{|c|c|c|c|}
\hline Range dB(A) & Allowed maximum limit & $\begin{array}{l}\text { Access road } \\
\text { construction }\end{array}$ & $\begin{array}{l}\text { Concrete pad } \\
\text { construction }\end{array}$ \\
\hline & & \multicolumn{2}{|c|}{ Surface (ha) } \\
\hline$<45$ & Background noise level & 3139.08 & 3127.96 \\
\hline $45-60$ & Low noise-allowed maximum noise limit in natural reserves, gardens and parks & 138.16 & 138.16 \\
\hline $60-65$ & Allowed maximum noise level in houses, hotels and recreation areas & 21.8 & 21.68 \\
\hline $65-70$ & Allowed maximum noise level in offices, shopping centres and restaurants & 15.36 & 16.4 \\
\hline $70-75$ & Allowed maximum noise level in industries & 10.64 & 13.72 \\
\hline$>75$ & Non-admissible & 14.76 & 56 \\
\hline
\end{tabular}

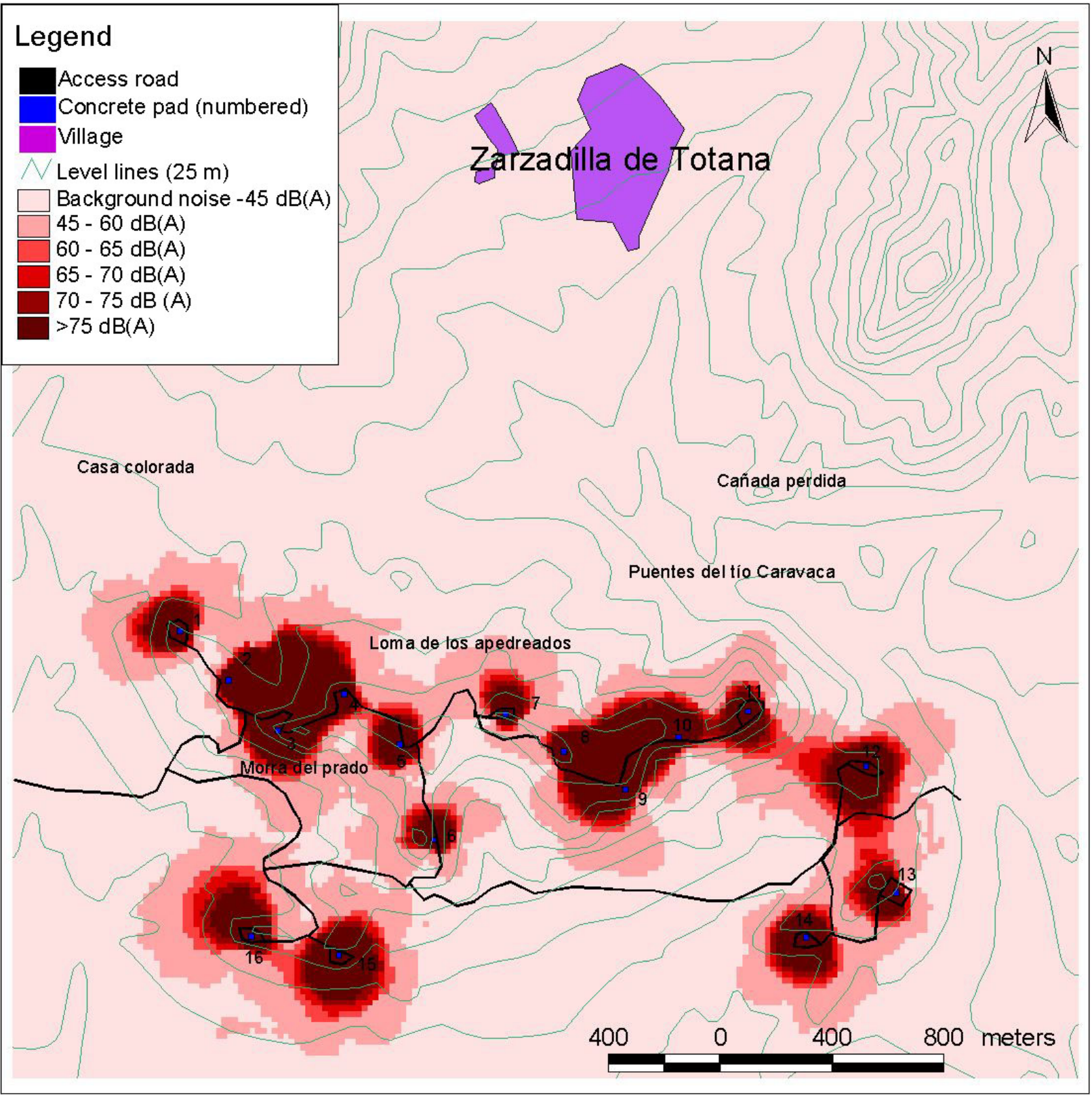

Figure 2. Noise map in construction phase: concrete pad construction/elimination. 
Table 4. Noise specifications for different power levels and distance from wind turbine (offered by wind turbine manufacturer).

\begin{tabular}{|c|c|c|c|c|c|}
\hline \multirow{2}{*}{ Wind speed $(\mathrm{m} / \mathrm{s})$} & \multirow{2}{*}{ Power (kW) } & \multicolumn{4}{|c|}{ Noise $(\mathrm{dB})$} \\
\hline & & $10 \mathrm{~m}$ & $50 \mathrm{~m}$ & $100 \mathrm{~m}$ & $500 \mathrm{~m}$ \\
\hline 4 & 73.3 & 60.9 & 47.0 & 40.9 & 27.0 \\
\hline 7 & 483.7 & 69.1 & 55.2 & 59.1 & 35.2 \\
\hline 21 & 2000 & 75.3 & 61.3 & 55.3 & 41.3 \\
\hline
\end{tabular}

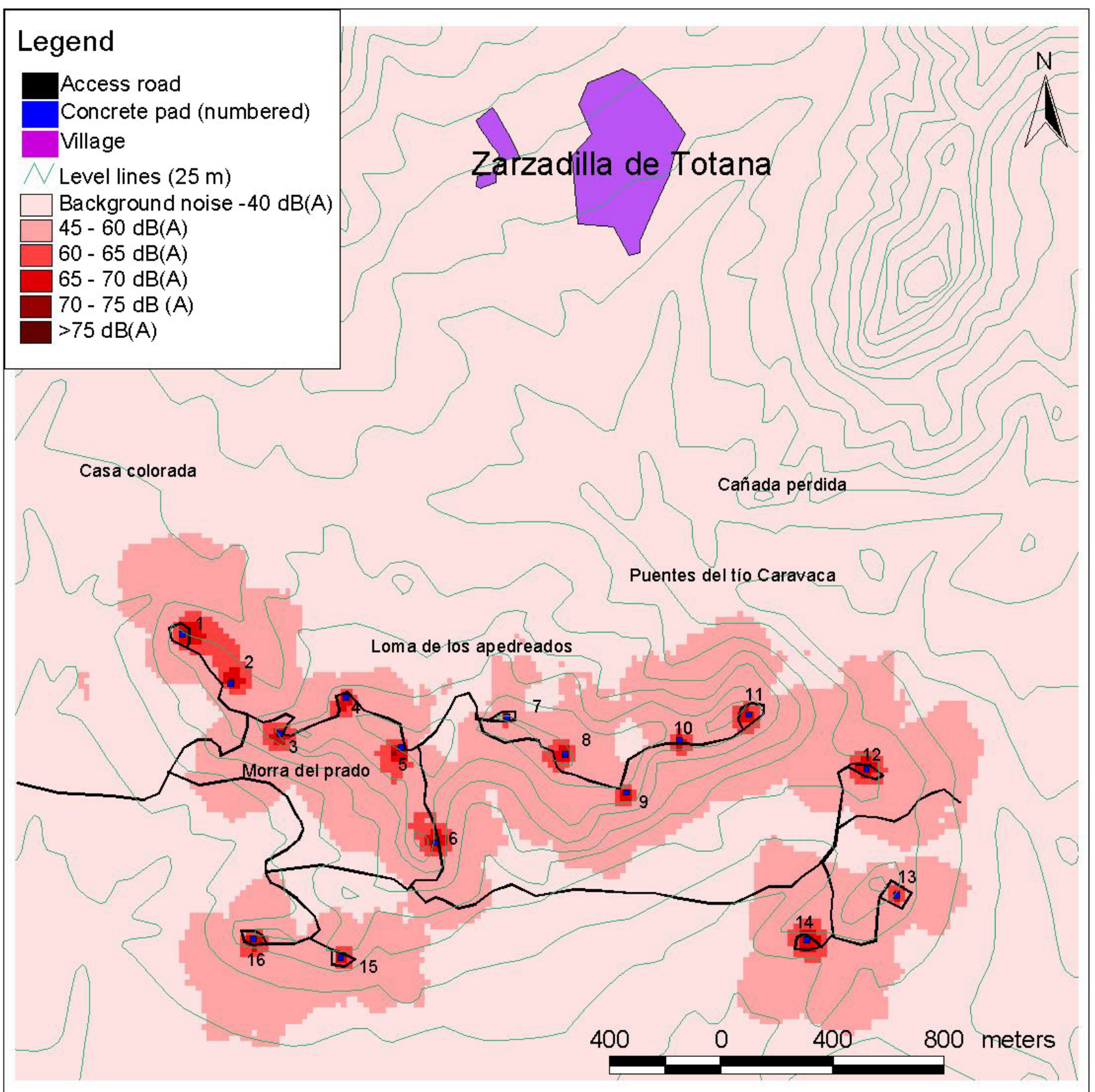

Figure 3. Noise map in operation phase: minimum power. 
Table 5. Surface included in each established noise category.

\begin{tabular}{|c|c|c|c|c|c|}
\hline \multicolumn{2}{|c|}{$40 \mathrm{~dB}(\mathrm{~A})$} & \multicolumn{2}{|c|}{$45 \mathrm{~dB}(\mathrm{~A})$} & \multicolumn{2}{|c|}{$50 \mathrm{~dB}(\mathrm{~A})$} \\
\hline Range (dB (A)) & Surface (ha) & Range (dB (A)) & Surface (ha) & Range (dB (A)) & Surface (ha) \\
\hline Background (40) & 3231.76 & Background (45) & 3211.92 & Background (50) & 3167.68 \\
\hline $40-60$ & 123.88 & $45-60$ & 118.88 & $50-60$ & 113.92 \\
\hline $60-65$ & 13.16 & $60-65$ & 21.96 & $60-65$ & 29.36 \\
\hline $65-70$ & 4.64 & $65-70$ & 13.92 & $65-70$ & 26.72 \\
\hline $70-75$ & 0 & $70-75$ & 5.48 & $70-75$ & 18.8 \\
\hline$>75$ & 0 & $>75$ & 0.92 & $>75$ & 17.44 \\
\hline
\end{tabular}

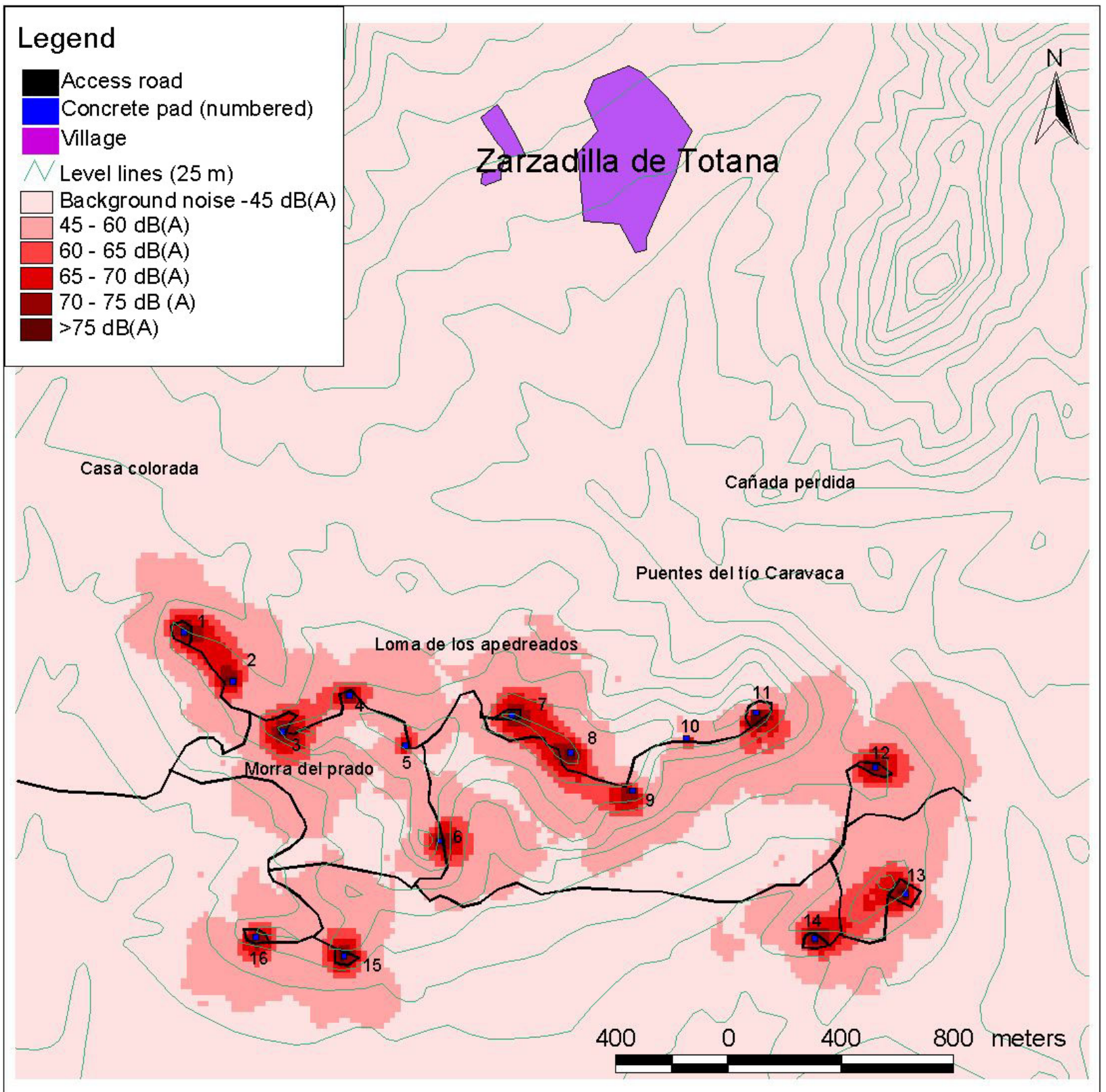

Figure 4. Noise map in operation phase: intermediate power. 


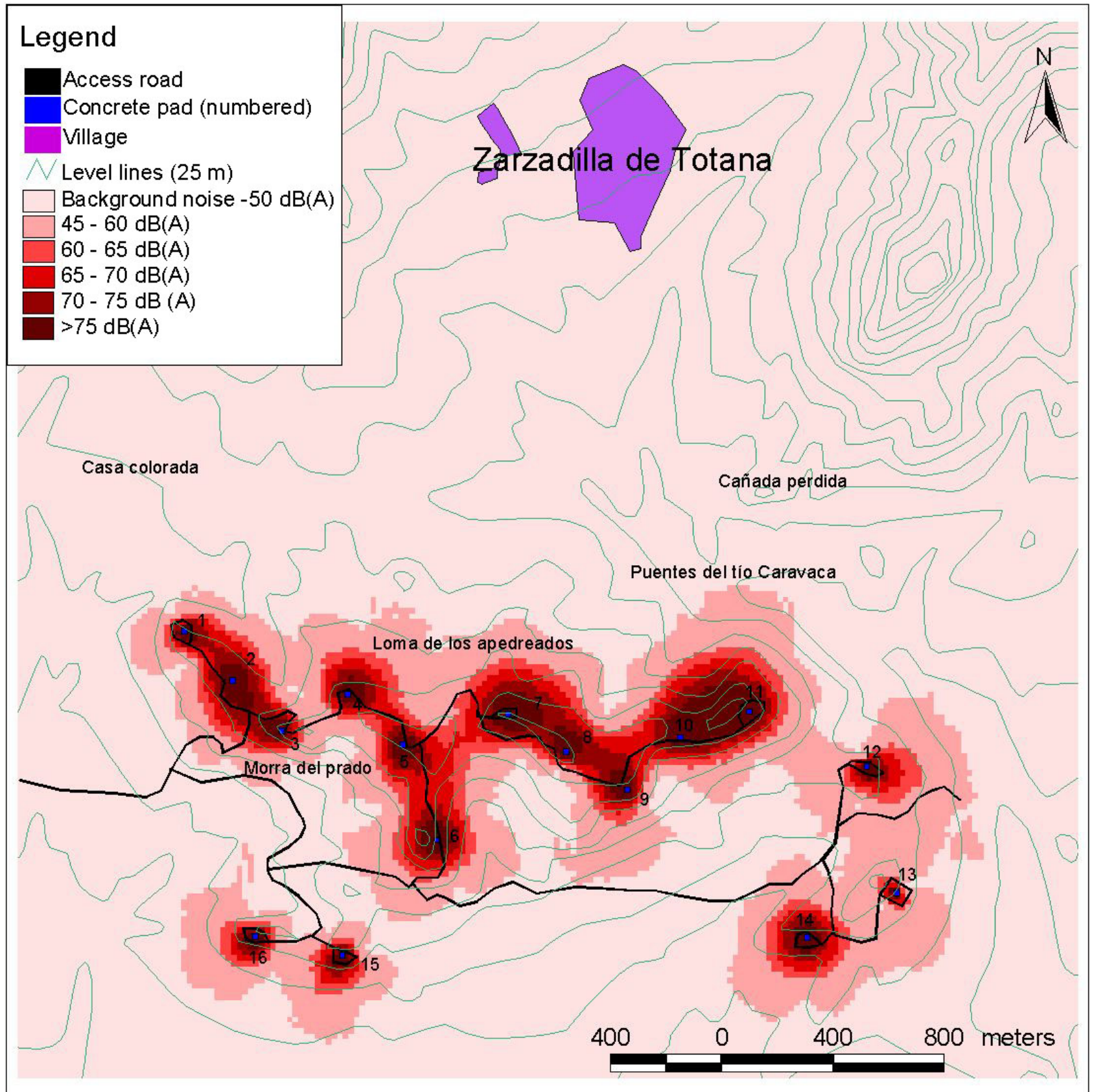

Figure 5. Noise map in operation phase: maximum power.

\section{Conclusions}

Proposed methodology for acoustic impact evaluation is a clear and objective technique, which considers the effect of distance in noise mitigation and the background noise level. It's not necessary to consider the attenuation effect of topographic barriers given that at low distances a noise attenuation takes place. That is, in the studied area and at a maximum power, at 500 meters of wind turbines, noise level is lower than the reference level established in the legislation.

ArcGIS software allows generating 3D maps of the studied area and its influ- 
ence region, being a useful instrument in the analysis and management process, offering successful results. Proposed methodology could help to determine and evaluate the best location for wind farms and other industrial activities which could generate acoustic impact.

For the studied wind farm and during the three established phases (construction, operation and decommission), almost all the area showed noise level lower than established background noise level. Even if noise levels do not exceed the allowed maximum limit for almost all the surface, best available methodology should be used.

\section{References}

[1] EU Roadmap (2011) Mapping Renewable Energy Pathways towards 2020. EREC.

[2] Sedaghatizadeh, N., Arjomandi, M., Cazzolato, B. and Kelso, R. (2017) Wind Farm Noises: Mechanisms and Evidence for Their Dependency on Wind Direction. Renewable Energy, 109, 311-322. https://doi.org/10.1016/j.renene.2017.03.046

[3] Hurtado, J.P., Fernández, J., Parrondo, J.L. and Blanco, E. (2004) Spanish Method of Visual Impact Evaluation in Wind Farms. Renewable and Sustainable Energy Reviews, 8, 483-491. https://doi.org/10.1016/j.rser.2003.12.009

[4] Molina-Ruiz, J., Martínez-Sánchez, M.J., Pérez-Sirvent, C., Tudela Serrano, M.L. and García Lorenzo, M.L. (2011) Developing and Applying a GIS-Assisted Approach to Evaluate Visual Impact in Wind Farms. Renewable Energy, 36, 1125-1132. https://doi.org/10.1016/j.renene.2010.08.041

[5] Tsoutsos, T., Tsouchlaraki, A., Tsiropoulos, M. and Serpetsidakis, M. (2009) Visual Impact Evaluation of a Wind Park in a Greek Island. Applied Energy, 86, 546-553. https://doi.org/10.1016/j.apenergy.2008.08.013

[6] Maslov, N., Claramunt, C., Wang, T. and Tang, T. (2017) Method to Estimate the Visual Impact of an Offshore Wind Farm. Applied Energy, 204, 1422-1430. https://doi.org/10.1016/j.apenergy.2017.05.053

[7] Sklenicka, P. and Zouhara, J. (2018) Predicting the Visual Impact of Onshore Wind Farms via Landscape Indices: A Method for Objectivizing Planning and Decision Processes. Applied Energy, 209, 445-454. https://doi.org/10.1016/j.apenergy.2017.11.027

[8] European Commission (1985) Council Directive 85/337/EEC of 27 June 1985 on the Assessment of the Effects of Certain Public and Private Projects on the Environment.

[9] Royal Decree 1131/1988, of 30 September, Establishing the Regulations of the Perform of the Royal Decree 1302/1986, of 28 June, of Environmental Impact Assessment.

[10] Directive 2002/49/EC of the European Parliament and of the Council of 25 June 2002 Relating to the Assessment and Management of Environmental Noise. Official Journal L 189; 18/07/2002.

[11] Law 37/2003, Noise Control Law of 17 November. 18/11/2003 BOE.

[12] Decree 48/1998 of 30 July of the Autonomous Region of Murcia on the Protection of the Environment against Noise. 